\title{
Acercamiento a la (no)equivalencia de los términos jurídicos en los diccionarios bilingües polaco-español/español-polaco
}

\section{An Approach to the (Non)Equivalence of Legal Terms in Bilingual Polish-Spanish and Spanish-Polish Dictionaries}

\author{
Maciej Paweł Jaskot \\ SWPS University of Social Sciences and Humanities, Faculty of Humanities and Social \\ Sciences, Department of Spanish Studies, ul. Chodakowska 19/31, 03-815 Warszawa, Poland \\ e-mail: mjaskot@swps.edu.pl
}

\author{
Agnieszka Wiltos \\ Department of General Linguistics, East Asian Comparative Linguistics and Baltic Studies \\ Constitutional Law Department, University of Warsaw, \\ ul. Krakowskie Przedmieście 26/28, 00-927 Warszawa, Poland \\ e-mail: awiltos@swps.edu.pl
}

\begin{abstract}
The new European legal context prompted the creation of an original terminology within the existing Polish and Spanish legal language. As far as legal translation and the methods used in the specialized translation are concerned, it is crucial to remember that the law as science and a culture element of each nation has its own language. One of the most effective and essential tools in the work of each legal translator are bilingual dictionaries. Notwithstanding, lexicographical resources, which should support the translator, often lack adequate equivalent. That is why, conducting studies based on the PolishSpanish and Spanish-Polish bilingual dictionaries in the context of linguistic analysis of lexical equivalents seems reasonable. The article approaches the phenomenon of equivalence or the lack of equivalence of selected lexical units in the legal field in order to demonstrate existing tools within general or specialized dictionaries available to - in our particular case - Polish translators whose working language is Spanish.
\end{abstract}

Keywords: equivalence, legal terminology, multilingual law, legal order, legal translation 


\section{INTRODUCCIÓN}

Aunque en los últimos años se haya notado un significante incremento del interés por la temática del lenguaje y metalenguaje jurídico, tanto por parte de los juristas como de los lingüistas, hoy en día siguen siendo escasas las publicaciones monográficas que traten no solo de la filosofía de los textos jurídicos sino también de su pragmática. Incluso es difícil encontrar trabajos de carácter comparativo que describan los lenguajes jurídicos español y polaco. Ese tipo de investigaciones parece ser necesario especialmente ahora, cuando tanto Polonia como España pertenecen a la misma familia de países que crean un nuevo orden jurídico que va estableciéndose en 24 idiomas oficiales igualmente vigentes: el orden jurídico de la Unión Europea (Wiltos, 2013, p. 6). El nuevo contexto internacional impulsó la creación de muchas publicaciones que describen el fenómeno del multilingüismo como uno de los fundamentos de la UE, expresados en los tratados, que reflejan su diversidad lingüística y cultural. Ese interés no se evidenció, sin embargo, en un igual desarrollo de las investigaciones lexicográficas bilingües especializadas, que se enfrentaran con el problema de la (no)equivalencia de los términos jurídicos dentro del sistema jurídico y lingüístico polaco-español.

Una de las herramientas más eficaces e imprescindibles en el trabajo de cada traductor jurídico son los diccionarios bilingües y/o especializados (analógicos o digitales). No obstante, los recursos lexicográficos mencionados, que deberían servir de ayuda al traductor, muchas veces carecen de un equivalente adecuado. En vista de ello, incluso parece más justificado realizar estudios sobre la base de diccionarios tanto bilingües (polaco-español/español-polaco), como de sinónimos, en el contexto del análisis lingüístico de los equivalentes léxicos dados.

En nuestro artículo queremos acercarnos al fenómeno de la equivalencia o no equivalencia de las unidades léxicas del campo jurídico seleccionadas con el fin de demostrar las herramientas existentes dentro de los diccionarios generales o especializados disponibles para los traductores que tienen como lengua de trabajo el español en el contexto de las posibles trampas en las que pueden caer en el proceso de traducción.

\section{MULTILINGÜISMO EN EL CAMPO JURÍDICO}

El multilingüismo jurídico en la Unión Europea y otras organizaciones supranacionales se caracteriza por la regla de la igualdad de la autenticidad de las lenguas oficiales de los Estados miembros, lo cual -al tratarse de la ley- significa que los actos jurídicos se preparan en todos los idiomas y todas las versiones son auténticas y consideradas en el proceso de traducción. Asimismo, ninguna de las versiones puede considerarse preferente (Doczekalska, 2009a, p. 344). Puesto que todas las lenguas son tratadas por igual, todas las versiones de un instrumento jurídico deberían tener el 
mismo sentido y el mismo efecto legal. Es evidente que tal necesidad crea un enorme desafío para los legisladores, juristas, lingüistas y traductores (Doczekalska, 2009 b, p. 116). El requisito de la igualdad entre los idiomas de la UE y las dificultades prácticas que se derivan del mismo conducen a la paradoja de la diversidad, indicada por Anthony Pym (2001). En la comunicación multilingüe dentro de las instituciones de las organizaciones internacionales pueden observarse dos tendencias contradictorias. Por un lado, emerge una lengua franca internacional, que -teóricamentedebería provocar una disminución de la diversidad lingüística. Por otro lado, hay un aumento en la práctica de la traducción, lo cual -a su vez- debería contribuir a una mayor diversidad lingüística. Y justo el proceso de traducción es, de hecho, la razón de estas dos tendencias contradictorias. Dado que es imposible utilizar al mismo tiempo todas las lenguas oficiales de la UE a efectos comunicacionales o jurídicos, se está utilizando, por lo general, un lenguaje particular que va convirtiéndose en una lengua franca. Sin embargo, la igualdad antes mencionada requiere la traducción a otros idiomas oficiales y de trabajo. Si bien las lenguas utilizadas para la redacción de los textos son principalmente el inglés, el francés y, a veces, el alemán -conocidas como "lenguas de procedimiento" en las instituciones (Doczekalska, 2009a, p. 351)-, la realidad es que cada vez más la legislación se redacta en inglés, ya que los documentos en este idioma alcanzan un $70 \%$ del número total de los textos legales. Además, el inglés es utilizado para definir conceptos jurídicos y se asocia con un contexto clásico de derecho civil (Pozzo, 2012, pp. 184-185). En un entorno tan multilingüe como la Unión Europea, la cuestión de la equivalencia gana especial importancia.

No obstante, consideramos que esta toma de conciencia hacia la traducción jurídica a nivel de la Comunidad Europea, paradójicamente, no se ve reflejada a la hora de efectuar traducciones de textos jurídicos basados en el derecho nacional. Nos referimos a la falta de unos posibles glosarios de terminología jurídica que resuelvan el problema de la equivalencia no tanto a nivel de textos redactados en la Unión Europea (textos que se diferencian por un tipo especial de vocabulario y sintaxis, que permite identificarlos como textos jurídicos comunitarios), sino más bien en el ámbito del derecho nacional. Dicho con otras palabras, los traductores de textos jurídicos no vinculados con la legislación comunitaria están abocados a valerse de herramientas del traductor generales (no especializadas) o de glosarios que -creados específicamente para la traducción a nivel de la UE- no siempre resultarán de ayuda, dado que pueden ser causa de incongruencias terminológicas.

\section{ACERCA DEL LENGUAJE JURÍDICO EN POLONIA Y ESPAÑA}

Nos parece pertinente subrayar que, a la hora de traducir, es posible adoptar dos puntos de partida diferentes (dos acercamientos a la materia lingüística) que determinarán la calidad de la traducción. Nos referimos a dos posibles maneras de enten- 
der algunos términos que puedan aparecer en un texto traducido, dependiendo de la (no)existencia de una definición legal adecuada (por ejemplo, su explicación dentro del acto legal en cuestión). Es decir, se trata de entender un texto según las normas y costumbres de uso vigentes en el lenguaje general, o tratarlo a priori como un texto redactado de acuerdo con una gramática y semántica textuales propias de una variedad específica de la lengua.

La ciencia del derecho polaca destaca dos tipos básicos de lenguaje jurídico: el lenguaje de las normas jurídicas (język prawny) y el lenguaje de los juristas que hablan de las normas jurídicas (język prawniczy).

Tomando el primer sentido del concepto de lenguaje jurídico, llamado algunas veces "lenguaje del legislador", Wróblewski (1948) entendía un lenguaje en el que se formulan los textos del derecho vigente. Lo describía como una variante del idioma étnico, natural, que, en algún sentido, se asemeja a los idiomas artificiales, creados para alguna rama de la ciencia o técnica. Lo que llamó su atención fue un vocabulario especifico (terminología jurídica), las diferencias gramaticales (por ejemplo, respecto a los verbos, el uso especial del presente de indicativo) y también las reglas particulares del estilo, que caracterizan los textos jurídicos (Chauvin, Stawecki \& Winczorek, 2009, p. 40). Hoy en día, dentro del lenguaje jurídico en el primero de los sentidos mencionados (język prawny), se distingue también el lenguaje jurídico de los reglamentos legales, en los que abundan los enunciados polimorfos, y el lenguaje jurídico de las normas legales, que tienen carácter directivo (Wronkowska, 2005, p. 40).

El lenguaje jurídico en el segundo sentido, según el concepto de Wróblewski, es el lenguaje en el que se formulan los enunciados sobre la ley vigente y sobre otros fenómenos jurídicos, es decir, el metalenguaje jurídico. Este, por tanto, sirve, entre otras cosas, para describir algunas instituciones legales, mostrar los resultados de las investigaciones llevadas a cabo en el ámbito del derecho o para presentar los efectos de la interpretación del derecho. En vista de ello, se puede distinguir el metalenguaje jurídico de la pragmática y de la doctrina del derecho (Chauvin, Stawecki \& Winczorek, 2009, p. 41; Wiltos, 2013, pp. 8-9).

El lenguaje jurídico no es el objeto de estudios solamente de la lingüística y la teoría del derecho polaca. En el caso de España, uno de los precursores de las investigaciones sobre la cuestión del lenguaje jurídico es Rodríguez-Aguilera, mencionado por Nowak-Michalska (2011, p. 14). Además, la investigadora enumera a investigadores tales como, por ejemplo, Capella, Hernando Cuadrado, Cazarola Prieto o Campos Podrillos. La autora ha observado que los investigadores mencionados, en la mayoría de los casos, se refieren al lenguaje jurídico usando dicho término o con el término similar "lenguaje del derecho" (Nowak-Michalska, 2011, p. 13). 


\section{LA CUESTIÓN DE LA EQUIVALENCIA}

El problema de la equivalencia parece ser una de esas cuestiones acerca de la cual se ha logrado un consenso interdisciplinario: las estructuras léxicas y semánticas de cualquier idioma son específicas solo para este idioma en particular y, por lo tanto, son parcialmente únicas. Por consiguiente, las estructuras léxicas y semánticas de dos (o más) lenguas no son isomorfas. La falta de isomorfismo en el léxico de una lengua (Zgusta, 1971, p. 294) es observable teórica y empíricamente, y se manifiesta de forma específica bajo la cuestión de la (no)equivalencia. En este artículo, nos interesa principalmente el aspecto lexicográfico de esta cuestión. No obstante, hace falta notar que el sustantivo equivalencia (y el adjetivo equivalente) se utiliza -además de su uso en el lenguaje cotidiano- en muchas disciplinas científicas, como la teoría de la ciencia, la lógica, la física, la ética, la teoría de la traducción, las matemáticas o el derecho, así como en la lexicografía. Aunque el significado de esta palabra empleada en diferentes contextos sea muy distinto, hay, no obstante, algunas características comunes que derivan de su etimología. De todas formas, "con el mismo significado" debe distinguirse claramente de "ser el mismo". Dos objetos son, en términos generales, idénticos si uno se corresponde con el otro en todos sus rasgos distintivos. Tendrán, pues, el mismo valor si tienen la misma designación sobre la base de al menos una función idéntica. Los objetos idénticos (o unidades léxicas, en el caso de nuestro estudio) tienen el mismo valor en el mismo contexto o acción. El concepto de similitud en la ciencia, sin embargo, no conduce automáticamente a una correspondiente equivalencia de significado. En términos generales, es posible lograr una visión general al acercarse al uso del vocablo equivalencia. Si alguien, por ejemplo, dice: "Esta expresión en la lengua A es equivalente a esa expresión en la lengua B cuando estas expresiones tienen el mismo significado", tal propuesta es comprensible desde el punto de vista del idioma en su uso general, pero no es viable en el sentido científico. Con todo, creemos que el concepto de equivalencia en la investigación de la traducción no debe ser construido de forma contraintuitiva respecto a su uso en el sentido lingüístico general.

La equivalencia (o su falta) es un fenómeno marginal fuera de los estudios comparativos, ya que la noción de equivalencia resulta crucial sobre todo en la lexicología contrastiva. A su vez, al centrarse en el sistema de la lengua, la noción de equivalencia resulta ser relativamente imprecisa. Una comprensión polisémica del signo lingüístico surge de la designación, dado que un elemento del léxico puede tener varios valores, es decir, significados. Al comparar un elemento de la lengua A con otro elemento de la lengua $\mathrm{B}$, la base de dicha comparación la constituye, por lo general, la relación denotativa. Por lo tanto, existe una equivalencia, que generalmente se llama equivalencia semántica a condición de que, en primer lugar, el número de sememas en la lengua A sea el mismo que en la lengua B (y, por lo tanto, tengan el mismo valor), y, en segundo lugar, su denotación (sememas pareados) sea la 
misma. Incluso entendido de esta manera, el concepto de equivalencia tiene ciertas desventajas. En primer lugar, la relación de equivalencia semántica se define por elementos que no son unidades semánticas. Otro punto débil es que la noción de equivalencia se basa en unidades semánticas, es decir, en sememas. Los sememas deben cumplir con el significado denotativo de la palabra, lo cual significa que tienen que ser equivalentes denotativos. En este caso, en lugar de equivalencia semántica, deberíamos hablar de equivalencia semiótica. Es por eso que ya a nivel sistémico, al tratarse de dos conceptos de equivalencia diferentes pero relacionados, es posible incurrir en malentendidos a la hora de entender y utilizar este vocablo.

Una frase clásica de un libro de texto para estudiantes e intérpretes podría ser: "La traducción comienza con el establecimiento de equivalencias al nivel de la palabra". Sin lugar a dudas, los problemas de la traducción comienzan al nivel de la palabra o grupos de palabras cuando aparecen unidades léxicas no equivalentes, es decir, elementos léxicos que no existen en la lengua meta. La sinequivalencia como fenómeno en los estudios de traducción es un problema complejo. El término es utilizado por diferentes autores (entre otros, A. Ivánov y V. Gak), pero no lo entienden de la misma manera: algunos ven las unidades léxicas no equivalentes como parte de una realidad inexistente; otros, solo como palabras que reflejan la especificidad cultural de un idioma. Los lingüistas búlgaros S. Vlakhov y S. Florin, en su libro Hепереводимое в переводе (Lo intraducible en la traducción), dan una descripción completa de los tipos de unidades léxicas que se pueden llamar sinequivalentes (безэквивалентные). La experiencia de los traductores y lexicógrafos claramente muestra que la transferencia de rasgos culturales (que se ven reflejados también en los sistemas y tradiciones jurídicos) ausentes en una de las lenguas del proceso de traducción no ha perdido su actualidad ${ }^{1}$.

Volviendo a la traducción jurídica, lo que impide establecer una equivalencia plena es la falta de equivalencia de conceptos utilizados en dos o más (en nuestro caso, el español y el polaco) ordenamientos jurídicos, lo que se debe a factores de diferente índole (historia, cultura, tradición legal, etc.); de ahí que, ya a nivel del punto de partida, la traducción se pueda ver amenazada por la incongruencia terminológica que llevará a malentendidos interpretativos. Esta amenaza se debe a diferencias a nivel estructural de los sistemas de las lenguas en cuestión. Cabe añadir que la terminología jurídica no está estandarizada a nivel internacional como la que

\footnotetext{
${ }^{1}[\ldots]$ discrepancies between cultures, or cultural gaps, give rise to lexical gaps in the vocabularies of the concerned languages, manifesting themselves most vividly in the process of establishing interlingual equivalence. This, in turn, makes life difficult for both bilingual lexicographers and translators. [...] culture-specificity is not as easy to pinpoint as it may seem. There are those who argue that in fact very few - if any - vocabulary items are culture independent: As language is created and used in context, it is inevitable to be tinted with the color of cultural idiosyncrasies. 'Culturally loaded word' is a misnomer because all words are culturally loaded, and there is no need to distinguish so-called culturally loaded words from those that are supposedly not" (Podolej, 2009, p. 45).
} 
pertenece a otras áreas. Por eso, no deja de ser un problema la falta de equivalencia terminológica entre el derecho polaco y el español, problema que -más adelanteseñalamos junto con algunos ejemplos. No ha de olvidarse, sin embargo, que en el caso de la traducción jurídica, los traductores recurren a la traducción funcional, es decir, persiguen con mayor exactitud el propósito del "funcionamiento" de un término en el sistema jurídico en cuestión (establecen, pues, una equivalencia dinámica). No obstante, este método -que hasta ahora sigue pareciendo el más adecuado para el tipo de traducciones del que nos ocupamos- requiere amplios conocimientos de derecho, dado que el traductor debe saber si el término en cuestión es aplicable al ordenamiento jurídico dado, lo cual supone una laboriosa tarea de investigación antes del proceso de traducción. En una traducción no especializada, sin embargo, tal investigación no se lleva a cabo por falta de conocimientos jurídicos del traductor y (en esto queremos hacer hincapié), a menudo, a un entendimiento erróneo de un vocablo, debido a que se le atribuye un significado utilizado en la lengua diaria y no el que adopta en los textos jurídicos. De ahí que, cuando el traductor se vale de una traducción literal u oblicua, surjan malentendidos y errores.

\section{4. (NO)EQUIVALENCIA DE LOS TÉRMINOS JURÍDICOS: EJEMPLOS}

Con el fin de acercarnos al problema de la (no)equivalencia de los términos jurídicos en los diccionarios bilingües polaco-español/español-polaco, hemos elegido cinco términos jurídicos con mucha tradición en el sistema jurídico polaco. Estos términos, además, son los que con mayor frecuencia se prestan a varias interpretaciones, debido a los diversos significados que se les pueda asignar en el idioma general. Es decir, en la práctica jurídica tienen un campo semántico que no se corresponde con el uso extrajurídico (por lo que, a veces, a los usuarios del idioma les parece contraintuitivo). Nuestro objetivo es demostrar los posibles problemas a los que se puede enfrentar cualquier traductor jurado en su trabajo. Somos conscientes de que el número de muestras seleccionadas no lleva a tener un cuadro completo del fenómeno. No obstante, éste no es el propósito final de nuestra sucinta investigación. Lo que pretendemos es señalar un problema que, cada vez más, está presente en la práctica traductológica. Una de las herramientas más eficaces e imprescindibles, que debería servir de ayuda a los traductores son los diccionarios bilingües y/o especializados, tanto analógicos como digitales; pese a ello, dichos recursos lexicográficos muchas veces carecen de un equivalente adecuado. Los términos que hemos elegido son:
a) zwłoka/opóźnienie
b) własność/posiadanie
c) zbrodnia/występek
d) małoletni/nieletni
e) narodowość/obywatelstwo 
Hemos basado nuestro análisis en diccionarios bilingües polaco-español/españolpolaco, diccionarios de sinónimos y diccionarios monolingües polacos y españoles. Es imprescindible recalcar que en el mercado polaco hay solo un diccionario especializado de términos jurídicos. Por consiguiente, nos hemos visto obligados a valernos de diccionarios generales, de la misma manera que lo hacen los traductores. El orden en el que presentamos los vocablos es el siguiente:

1) Wielki stownik polsko-hiszpański, Wiedza Powszechna (WSPH)

2) Diccionario de terminología jurídica polaco-español (DTJ)

3) Stownik języka polskiego: synonimy - sjp.pwn.pl (SJP)

4) Stownik wspótczesnego języka polskiego (SWJP)

5) Diccionario de uso del español actual (DUEA)

\subsection{ZWŁOKA/OPÓŹNIENIE}

Tabla 1. Comparación de los términos polacos zwłoka/opóźnienie, sus respectivas traducciones al español, sus significados según los diccionarios monolingües polacos SJP y SWJP, y su significado según el DUEA

\begin{tabular}{|l|l|l|}
\hline & \multicolumn{1}{|c|}{ Zwtoka } & \multicolumn{1}{|c|}{ Opóźnienie } \\
\hline 1 & $\begin{array}{l}\text { (opóźnienie): retraso, demora, retardo, retarda- } \\
\text { ción, atraso, atraso, aplazamiento, dilación, } \\
\text { tardanza, postergación, prórroga, prolongación; }\end{array}$ & - opóźniać: retrasar, atrasar, retardar, demorar \\
\hline 2 & $\begin{array}{l}\text { demora, retraso, mora, atraso, dilación, retarda- } \\
\text { ción, tardanza; }\end{array}$ & $\begin{array}{l}\text { retraso, demora, dilación, retardo, retardación, } \\
\text { tardanza; }\end{array}$ \\
\hline 3 & $\begin{array}{l}\text { zwłoka }=\text { opóźnienie } \\
\text { opónienie = poślizg, zwłoka, spóźnienie }\end{array}$ \\
\hline 4 & $\begin{array}{l}\text { odwlekanie wykonania czegoś na później, opóź- } \\
\text { nienie, zwlekanie; }\end{array}$ & $\begin{array}{l}\text { od opóźnić; opóźniać: sprawiać, że coś, co mia- } \\
\text { to być wykonane w określonym czasie, odbywa } \\
\text { się później; powodować opóźnienie, zwlekać } \\
\text { z czymś; }\end{array}$ \\
\hline 5 & $\begin{array}{l}\text { demora: tardanza o retraso en la realización o en cumplimiento de algo, esp. de una obligación; } \\
\text { retraso: llegada a un lugar más tarde de lo previsto; demora o atraso en la ejecución de una acción; } \\
\text { desarrollo inferior al normal; } \\
\text { dilación: demora, tardanza o detención por algún tipo; } \\
\text { retardación: - } \\
\text { tardanza: retraso o empleo de mucho tiempo en la realización de una acción; }\end{array}$ \\
\hline
\end{tabular}

Como demuestran los ejemplos dados, en el ámbito del idioma natural los vocablos en cuestión parecen funcionar dentro de los sistemas de los idiomas polaco y español sinonímicamente. Nada más lejos de la realidad jurídica, en la que ambos desempeñan un papel diferente en la rama del derecho civil. Según el artículo 476 del Código Civil polaco: „Dłużnik dopuszcza się zwłoki, gdy nie spełnia świadczenia $\mathrm{w}$ terminie, a jeżeli termin nie jest oznaczony, gdy nie spełnia świadczenia niezwłocznie po wezwaniu przez wierzyciela. Nie dotyczy to wypadku, gdy opóźnienie 
w spetnieniu świadczenia jest nastepstwem okoliczności, za które dtużnik odpowiedzialności nie ponosi" ${ }^{2}$. Este artículo introdujo en el sistema del derecho polaco la distinción entre opóźnienie, que se entiende como un retraso no provocado o sin culpa por parte de uno de los contrayentes y zwłoka, término entendido como retraso o bien provocado o bien intencionado por una de las partes del contrato.

\subsection{WŁASNOŚĆ/POSIADANIE}

Tabla 2. Comparación de los términos polacos własność/posiadanie, sus respectivas traducciones al español y sus significados según los diccionarios monolingües polacos SJP y SWJP, y su significado según el DUEA

\begin{tabular}{|l|l|l|}
\hline & \multicolumn{1}{|c|}{ Wlasność } & \multicolumn{1}{c|}{ Posiadanie } \\
\hline 1 & (mienie): propiedad, posesión, bien, bienes; & posesión; (stan posiadania): riquezas, bienes; \\
\hline 2 & propiedad, pertenencia, dominio, titularidad; & posesión, tenencia; \\
\hline 3 & własność = - & posiadanie = - (posiadać = mieć) \\
\hline 4 & $\begin{array}{l}\text { rzecz posiadana przez kogoś, należąca tylko do } \\
\text { danej osoby; mienie, majątek; }\end{array}$ & $\begin{array}{l}\text {----------------- } \\
\text { posiadać: mieć coś na wlasność, być wlaścicie- } \\
\text { lem czegoś; }\end{array}$ \\
\hline 5 & $\begin{array}{l}\text { propiedad: derecho o facultad de poseer algo } \\
\text { y poder disponer de ello dentro de los límites } \\
\text { legales; }\end{array}$ & $\begin{array}{l}\text { posesión: propiedad o acto de poseer algo con } \\
\text { intención de conservarlo como propio; }\end{array}$ \\
\hline
\end{tabular}

Los ejemplos analizados arriba reflejan el mismo problema que los anteriores. Nuestra competencia de hablantes nativos de polaco y la experiencia como profesores de lenguas extranjeras nos permite constatar que en muchos casos para los usuarios nativos del idioma polaco las palabras własność y posiadanie son sinónimas. Se puede sacar la misma conclusión revisando los vocablos presentes en la tabla 2 . Sin embargo, własność y posiadanie son instituciones del derecho civil de diferentes características de las que proceden diferentes derechos y obligaciones de los participantes de la circulación civil. Según el artículo 140 del Código Civil polaco: „W granicach określonych przez ustawy i zasady współżycia społecznego właściciel może, z wyłączeniem innych osób, korzystać z rzeczy zgodnie ze społecznogospodarczym przeznaczeniem swego prawa, w szczególności może pobierać pożytki i inne dochody z rzeczy. W tych samych granicach może rozporządzać rzeczą”. En cambio, de acuerdo con el artículo 336 del mismo: „Posiadaczem rzeczy jest zarówno ten, kto nią faktycznie włada jak właściciel (posiadacz samoistny), jak i ten, kto nią faktycznie włada jak użytkownik, zastawnik, najemca, dzierżawca lub mający inne prawo, z którym łączy się określone władztwo nad cudzą rzeczą (posiadacz zależny)". Las instituciones analizadas tienen también sus definiciones en el

\footnotetext{
${ }^{2}$ La cursiva es nuestra.
} 
Código Civil español. Según el artículo 348 del mismo: "La propiedad es el derecho de gozar y disponer de una cosa, sin más limitaciones que las establecidas en las leyes"; mientras que la posesión se define en el artículo 430 como: "La tenencia de una cosa o el disfrute de un derecho por una persona. Posesión civil es esa misma tenencia o disfrute unidos a la intención de haber la cosa o derecho como suyos (Posesión natural)".

\subsection{ZBRODNIA/WYSTĘPEK}

La palabra polaca zbrodnia merece, a nuestro parecer, una atención especial debido a su peculiar (intuitivo) uso dentro del idioma general.

Tabla 3. Comparación de los términos polacos zbrodnia/występek, sus respectivas traducciones al español, sus significados según los diccionarios monolingües polacos SJP y SWJP, y su significado según el DUEA

\begin{tabular}{|l|l|l|}
\hline & \multicolumn{1}{|c|}{ Zbrodnia } & \multicolumn{1}{|c|}{ Występek } \\
\hline 1 & crimen, acto criminal, delito, delito grave & mala acción, fechoría, delito, crimen \\
\hline 2 & crimen & delito de menor gravedad \\
\hline 3 & zbrodnia = podłość & $\begin{array}{l}\text { występek = wszeteczność, wszeteczeństwo, } \\
\text { sprawka }\end{array}$ \\
\hline 4 & $\begin{array}{l}\text { ciężkie przestępstwo, poważne wykroczenie } \\
\text { przeciwko drugiemu człowiekowi (grupie } \\
\text { ludzi), najczęściej zabójstwo, zranienie, bądź } \\
\text { dokonanie gwałtu; }\end{array}$ & $\begin{array}{l}\text { czyn będący przekroczeniem norm moralnych, } \\
\text { zasad współżycia społecznego lub praw obo- } \\
\text { wiązujących lub praw obowiązujących w pew- } \\
\text { nej społeczności; }\end{array}$ \\
\hline 5 & $\begin{array}{l}\text { crimen: acción voluntaria de matar o herir } \\
\text { gravemente a una persona; acción que resulta } \\
\text { gravemente perjudicial o censurable; }\end{array}$ & $\begin{array}{l}\text { delito: culpa, crimen o quebrantamiento de la } \\
\text { ley; acción u omisión voluntaria, castigada por } \\
\text { la ley con pena grave; }\end{array}$ \\
\hline
\end{tabular}

Aunque las definiciones de los vocablos citadas en la tabla 3 demuestran un significado bastante amplio de los términos zbrodnia y występek, parece que para los usuarios nativos del idioma polaco, especialmente el término zbrodnia tiene una connotación muy estricta, limitada al delito de mayor gravedad contra la vida de una persona. Como nos indica nuestra experiencia, dentro del idioma natural el término zbrodnia aparece intuitivamente como sinónimo de morderstwo ('asesinato, homicidio'). En cambio, el Código Penal polaco, definiendo el delito, introduce ambos términos analizados arriba refiriéndose a la cuestión de la pena y no al problema de la acción en cuanto a la distinción de los dos. Según el artículo 7 del Código Penal polaco: „Przestępstwo jest zbrodnią albo występkiem (§ 1). Zbrodnią jest czyn zabroniony zagrożony karą pozbawienia wolności na czas nie krótszy od lat 3 albo karą surowszą (§ 2). Występkiem jest czyn zabroniony zagrożony grzywną powyżej 
30 stawek dziennych, karą ograniczenia wolności albo karą pozbawienia wolności przekraczającą miesiąc (§ 3)”. El artículo 8 añade también que: „Zbrodnię można popełnić tylko umyślnie; występek można popełnić także nieumyślnie, jeżeli ustawa tak stanowi".

En este lugar vale la pena recordar que en el Código Penal español el delito se define de manera totalmente diferente: según el artículo 8 del mismo: "Son delitos las acciones y omisiones dolosas o imprudentes penadas por la ley". "Son delitos graves las infracciones que la Ley castiga con pena grave $(\S 1)$. Son delitos menos graves las infracciones que la Ley castiga con pena menos grave $(\S 1)$. Son delitos leves las infracciones que la ley castiga con pena leve ( $(1)$. Cuando la pena, por su extensión, pueda incluirse a la vez entre las mencionadas en los dos primeros números de este artículo, el delito se considerará, en todo caso, como grave. Cuando la pena, por su extensión, pueda considerarse como leve y como menos grave, el delito se considerará, en todo caso, como leve (§ 1)".

\subsection{MAŁOLETNI/NIELETNI}

Tabla 4. Comparación de los términos polacos matoletni/nieletni, sus respectivas traducciones al español, sus significados según los diccionarios monolingües polacos SJP y SWJP, y su significado según el DUEA

\begin{tabular}{|c|c|c|}
\hline & Matoletni & Nieletni \\
\hline 1 & menor de edad, menor; & $\begin{array}{l}\text { menor de edad, menor, juvenil, (nieletni prze- } \\
\text { stępca - delincuente juvenil, sąd dla nieletnich - } \\
\text { tribunal de menores); }\end{array}$ \\
\hline 2 & menor de edad; & menor de edad; \\
\hline 3 & - & - \\
\hline 4 & $\begin{array}{l}\text { będący w wieku, w którym nie ma się pełni } \\
\text { praw obywatelskich; nieletni; niepełnoletni; } \\
\text { młodociany; }\end{array}$ & $\begin{array}{l}\text { taki, w stosunku do którego ze względu na } \\
\text { młody wiek (w Polsce do } 17 \text { roku życia) nie } \\
\text { mają zastosowania przepisy prawa karnego } \\
\text { dotyczące osób dorosłych; }\end{array}$ \\
\hline 5 & \multicolumn{2}{|c|}{$\begin{array}{l}\text { menor: referido a una persona que no tiene la edad que fija la ley para poder ejercer todos sus } \\
\text { derechos civiles; }\end{array}$} \\
\hline
\end{tabular}

Como demuestran los ejemplos dados, los términos polacos małoletni y nieletni pertenecen más bien al ámbito lingüístico jurídico que general. Las definiciones de ambos vocablos presentadas en SWJP se refieren de manera muy clara a situaciones de carácter jurídico o legal. Lo interesante es que dichos términos, aunque en el idioma coloquial se usan muchas veces indistintamente, no presenten ningún sinónimo. Conservan su valor de términos distintos debido a lo escrito respectivamente en los Códigos Civil y Penal polacos. Por persona menor de edad dentro de la rama del derecho civil se entiende la persona que todavía no ha cumplido 18 años 
(artículo 10 del Código Civil), mientras que el menor de edad dentro de la rama del derecho penal es quien no ha cumplido 17 años (artículo $10 \S 2$ del Código Penal). Teniendo en cuenta la diferencia que existe entre los términos polacos małoletni y nieletni sorprende la falta de distinción entre estos en el idioma español, que encontramos en el DTJ. Aunque en el sistema jurídico español no se aplica distintamente dichos términos conforme con la rama del derecho correspondiente, nos parece pertinente subrayar la falta de una equivalencia precisa entre estos al realizar la traducción al polaco.

\subsection{NARODOWOŚĆ/OBYWATELSTWO}

Tabla 5. Comparación de los términos polacos narodowośćlobywatelstwo, sus respectivas traducciones al español, sus significados según los diccionarios monolingües polacos SJP y SWJP, y su significado según el DUEA

\begin{tabular}{|l|l|l|}
\hline & \multicolumn{1}{|c|}{ Narodowość } & \multicolumn{1}{c|}{ Obywatelstwo } \\
\hline 1 & nacionalidad & ciudadanía \\
\hline 2 & nacionalidad & ciudadanía \\
\hline 3 & narodowość = nacja & - \\
\hline 4 & $\begin{array}{l}\text { przynależność do jakiegoś narodu, świadomość } \\
\text { tej przynależności; zespół właściwości charakte- } \\
\text { rystycznych dla jakiegoś narodu, tworzacych } \\
\text { jego specyfikę, odrębność w stosunku do innych; }\end{array}$ & $\begin{array}{l}\text { przynależność państwowa osób związana z obo- } \\
\text { wiązkami i uprawnieniami określonymi w kon- } \\
\text { stytucji i prawie danego państwa; }\end{array}$ \\
\hline 5 & $\begin{array}{l}\text { nacionalidad: estado o situación de quien posee } \\
\text { el derecho de ciudadanía de una nación; }\end{array}$ & $\begin{array}{l}\text { ciudadanía: condición y derecho de ciudadano; } \\
\text { comportamiento de un buen ciudadano; conjun- } \\
\text { to de los ciudadanos; }\end{array}$ \\
\hline
\end{tabular}

El último de los ejemplos elegidos nos parece de especial interés debido a su peculiar uso dentro de los sistemas jurídicos de la lengua española. Aunque ambos términos parecen no causar ningún problema traductológico, se puede observar algunas irregularidades en el uso del término español que corresponde funcionalmente con el término polaco obywatelstwo. Según el artículo 11 de la Constitución Española,

la nacionalidad [en polaco: obywatelstwo] española se adquiere, se conserva y se pierde de acuerdo con lo establecido por la ley (1). Ningún español de origen podrá ser privado de su nacionalidad [en polaco: obywatelstwo] (2). El Estado podrá concertar tratados de doble nacionalidad [en polaco: obywatelstwo] con los países iberoamericanos o con aquellos que hayan tenido o tengan una particular vinculación con España. En estos mismos países, aun cuando no reconozcan a sus ciudadanos un derecho recíproco, podrán naturalizarse los españoles sin perder su nacionalidad [en polaco: obywatelstwo] de origen (3).

En este ejemplo se puede observar que el equivalente funcional del término polaco obywatelstwo es el término español nacionalidad en vez de ciudadanía, que se 
supone más natural según los diccionarios citados. El uso de los términos analizados parece incluso más interesante en uno de los artículos del Tratado de la Unión Europea, según el cual, la Unión respetará en todas sus actividades el principio de la igualdad de sus ciudadanos, que se beneficiarán por igual de la atención de sus instituciones, órganos y organismos. Será ciudadano de la Unión toda persona que tenga la nacionalidad (en polaco: obywatelstwo) de un Estado miembro. La ciudadanía (en polaco: obywatelstwo) de la Unión se añade a la ciudadanía nacional sin sustituirla (artículo 9).

\section{CONCLUSIONES}

La traducción de términos jurídicos supone una doble transposición entre dos lenguas y dos ordenamientos jurídicos donde el sistema lingüístico se ve afectado por las reglas impuestas por el derecho (Cornea, 2010). Por consiguiente, el traductor de textos jurídicos ha de poseer conocimientos de derecho y traducción para poder producir el mismo efecto legal, puesto que establecer una relación de equivalencia entre los conceptos (Šarčević, 1997), a través de las características esenciales de las unidades léxicas, podría ser una práctica aceptable para un traductor no jurista, pero inviable para una traducción jurídica lograda siendo imprescindible el conocimiento de la estructura conceptual de la organización y funcionamiento del derecho. Por otra parte, los estudios de derecho comparado, van dirigidos principalmente a los juristas, de ahí que escaseen recursos para los traductores no juristas, que han de enfrentarse a las múltiples dificultades del proceso de análisis contrastivo de dos conceptos y establecer una relación de equivalencia entre ellos. De todas formas, los diccionarios monolingües o bilingües siguen siendo las herramientas que los traductores utilizan para descodificar el texto de partida y estos no reúnen las soluciones técnicas de traducción requeridas por la traductología jurídica, lo cual -desde luego- no nos sorprende. Sin embargo, notamos que el diccionario especializado que hemos utilizado en nuestro breve estudio (DTJ, posición 2 de las tablas) brinda información más bien de carácter general y carece de información útil para el proceso de transcodificación.

Sobre la base de lo anterior, podemos observar que, para una posible traducción jurídica, los cinco diccionarios tratados presentan las siguientes desventajas:

a) presentan más de un equivalente (entendido en el significado corriente de la palabra);

b) no ofrecen discriminación semántica entre los equivalentes;

c) presentan relaciones falsas de equivalencia (siendo los vocablos en cuestión términos jurídicos) y

d) en el caso del diccionario especializado (DTJ), carecen de información complementaria que pueda servir al traductor para la comprensión de los equivalentes (diferencias que puedan surgir del ordenamiento jurídico). 
El propósito de nuestro breve análisis ha sido el de acercarse a la problemática de la traducción de términos jurídicos teniendo en cuenta el concepto de equivalencia. Este, a su vez, pone de relieve otra serie de problemas, ya que a la hora de realizar una traducción especializada en el ámbito del derecho es imprescindible tener en cuenta los siguientes factores: las diferencias sistemáticas de los ordenamientos jurídicos, la falta de equivalencia de los términos traducidos (falta de isomorfismo), y -lo que nos ha parecido uno de los aspectos más importantes- la variedad de significados atribuidos a un vocablo dentro de un sistema lingüístico, debida a su utilización en distintos contextos, es decir, en el idioma natural y en el lenguaje especializado (lenguaje jurídico, en nuestro caso).

No nos cabe duda de que la problemática que hemos señalado merece investigaciones ulteriores con el fin de elaborar herramientas más precisas para su estudio. 


\section{BIBLIOGRAFÍA}

Chauvin, T., Stawecki, T. \& Winczorek, P. (2009). Wstęp do prawoznawstwa. Warszawa: C. H. Beck. Cornea, I. (2010). Bases metodológicas para la traducción jurídica: traductología, derecho comparado y lexicografía bilingüe (Trabajo de fin de máster). Bacelona: Universitat Pompeu Fabra (Departament de Traducció i Ciències del Llenguatge). Disponible en https://repositori. upf.edu/bitstream/handle/10230/6317/TREBALL\%20COMPLET.pdf?sequence=1

Doczekalska, A. (2009a). Drafting and interpretation of EU law - paradoxes of legal multilingualism. En: Grewendorf, G. \& Rather, M. (Eds.), Formal Linguistics and Law (pp. 339-370). Berlin \& New York: Mouton de Gruyter.

- (2009b). Drafting of Translation - Production of Multlingual Legal Texts. En: F. Olsen, A. Lorz \& D. Stein (Ed.), Translation Issues in Language and Law (pp. 116-135). Basingstoke \& New York: Palgrave Macmillan.

DTJ = Komarnicki, M., Komarnicki, I. \& Komarnicka, E. (2006). Diccionario de Terminología Jurídica polaco-español. Warszawa: C. H. Beck.

DUEA = Moliner, M. (1998). Diccionario de uso del español actual (2 $2^{\mathrm{a}}$ ed.). Madrid: Gredos.

Gak, V. G. (1998). Iazykovye prebrazovaniia. Moskva: Iazyki russkoĭ kul'tury.

Ivanov, A. O. (2006). Bezékvivalentnaia leksika. Sankt Peterburg: Izdatel'stvo SpbGU.

Lastra Lastra, J. M. (2003). Derecho a la lengua y lenguaje jurídico. Derecho a la lengua y lenguaje jurídico. En: R. Márquez Romero \& E. García Castillo (Eds.), El derecho a la lengua de los pueblos indígenas. XI Jornadas Lascasianas (pp. 1-16). México, Universidad Nacional Autónoma de México. Disponible en biblio.juridicas.unam.mx/libros/2/740/5.pdf

Nowak-Michalska, J. (2012). Modalność deontyczna w języku prawa na przykładzie polskiego i hiszpańskiego kodeksu cywilnego. Poznań: Rys.

Pozzo, B. (2012). English as a Legal Lingua Franca in the EU Multilingual Context. En: C. J. W. Baaij (Ed.), The Role of Legal Translation in Legal Harmonization (pp. 183-202). Alphen aan den Rijn: Kluwer Law International.

Pym, A. (2001). Translation and International Institutions. Explaining the Diversity Paradox. Paper presented to the workshop Translation and Institutions at the conference Language Study in Europe at the Turn of the Millenium, Societas Linguistica Europea, Katholieka Universiteit Leuven, 28-31 of August 2001. Disponible en http://usuaris.tinet.cat/apym/on-line/translation /diversity.html

SJP = Stownik języka polskiego, PWN online. sjp.pwn.pl

SWJP = Dunaj, B. (1996). Stownik wspótczesnego języka polskiego. Warszawa: Wilga.

Šarčević, S. (1997). New Approach to Legal Translation. The Hague: Kluwer Law International.

Vlakhov, S. \& Florin, S. (1980). Непереводимое в переводе. Москва: Международные отношения.

Wiltos A. (2013). Determinantes lingüísticos de la modalidad deóntica en las normas-reglas y normas-principios a base de las constituciones de la República de Polonia y del Reino de España (Trabajo de fin de máster inédito). Varsovia: Universidad de Varsovia (Instituto de Estudios Ibéricos e Iberoamericanos).

Wronkowska, S. (2005). Podstawowe pojęcia prawa i prawoznawstwa. Poznań: Ars boni et aequi. Wróblewski, B. (1948). Język prawny i prawniczy. Kraków: PAU.

WSPH = Perlin, O. (2006). Wielki stownik polsko-hiszpański. Warszawa: Wiedza Powszechna.

Zgusta, L. (1971). Manual of Lexicography. Janua Linguarum, Series Maior, 39. The Hague \& Paris: Mouton. 
